stitution, chaired two panels organized as a tribute to Warren Miller and cosponsored by APSA and the National Election Studies. The Harold D. Lasswell Symposium, organized by the program co-chairs and chaired by Charles O. Jones, University of Wisconsin, was held later Friday evening and focused on "Who Cares about Impeachment? Implications for Amcrican Politics and Civic Culture."

Also on Friday evening, the Women's Caucus celebrated their thirtieth anniversary with a lively dinner attracting 187 political scientists and hosted by Toni-Michelle Travis, George Mason University. Several women (and a few men) were honored as founding officers, including Dorothy Stetson, Carol BarnerBarry, Berenice Carroll, Kay

Klotzhurger, Judith Stiehm, and Audrey Wells.

This year's Hyde Park sessions, designed for informal and controversial discussion, were well-attended at the Hilton Atlanta Hotel. The topies were "New Labor in the New South" and "The Clinton Impeachment: Pro \& Con."

The 1999 Conference for Department Chairs and Professional Day on Wednesday featured 17 short

Matthew Hoiden Jr. and Catherine E. Rudder present 1999 Frank J. Goodnow Awards to Gabriel A. Almond (left-center) and Doris A. Graber (right-center). The award recognizes individuals who have made outstanding contributions to the development of the political science profession and the building of APSA.

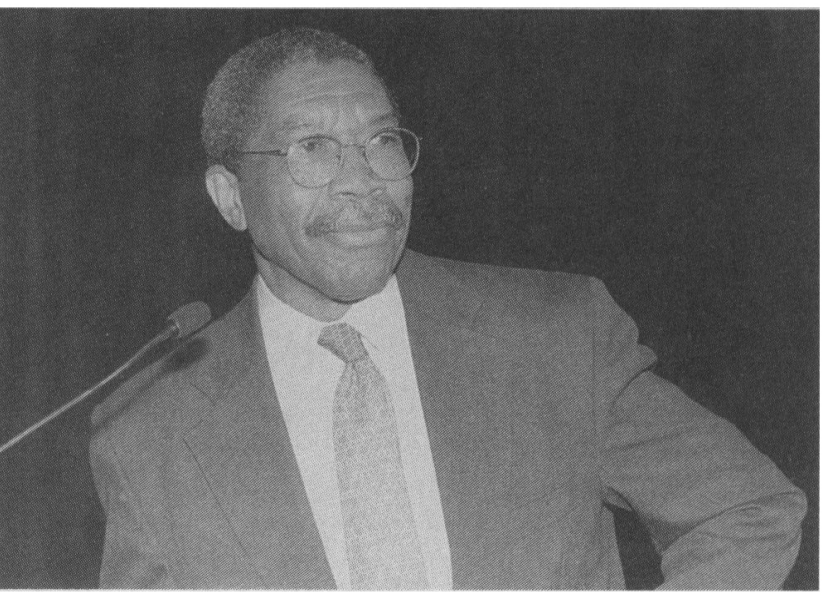

1999 APSA President Matthew Holden Jr. delivers his Presidential Address in Atlanta.

courses and two chairs' sessions. Two of the short courses, sponsored by APSA Organized Sections, were held at area universities. Short courses and other preconvention workshops continue to be a popular addition to the Annual Meeting for in-depth study or hands-on training. For the second year, Political Methodology videotaped two short courses for distribution and classroom use.

Several new innovations and programs were introduced during the Atlanta meeting, notably the Electronic Message Center. The Message Center was well-utilized by the attendees, as indicated by the high volume of messages transmitted $(6,714)$, and will become a standard service at future meetings. The newly-expanded Cyber Stop was frequented during all hours of operation. Exhibitor-sponsored coffee breaks and receptions were welcome additions this year and are expected to continue for future years.

Plans for the 2000 Annual Meet- ing, to be held August 31September 3 in Washington, DC, are well underway, and panel sessions will be split between two newly-renovated properties: the Marriott Wardman Park Hotel (formerly the Sheraton Washington) and the Omni Shoreham Hotel. The Hilton Washington will host the Professional Placement Service and additional panel sessions. Shuttles will run continuously from each of the three co-headquarters hotels. For details on the 2000 mecting, be sure to visit the Annual Meeting web site (www.apsanet.org/mtgs) and to look for more information in the March and June issues of PS.

\section{Achievements of Researchers and Teachers Recognized during APSA Honors Reception}

Honoring those scholars who have helped shape the profession, APSA hosted its 1999 Honors Reception at the Academy of Medicine in Atlanta as part of the Annual Meeting. At the awards ceremony following the reception, the Association recognized special achievements in the profession. Presentation of the third annual Frank J. Goodnow Award for Distinguished Service highlighted the evening, with Gabriel A. Almond, Doris A. Graber, Malcolm E. Jewell, and Thomas E. Mann being honored. Named for the Association's first president, the award recognizes individuals who have made
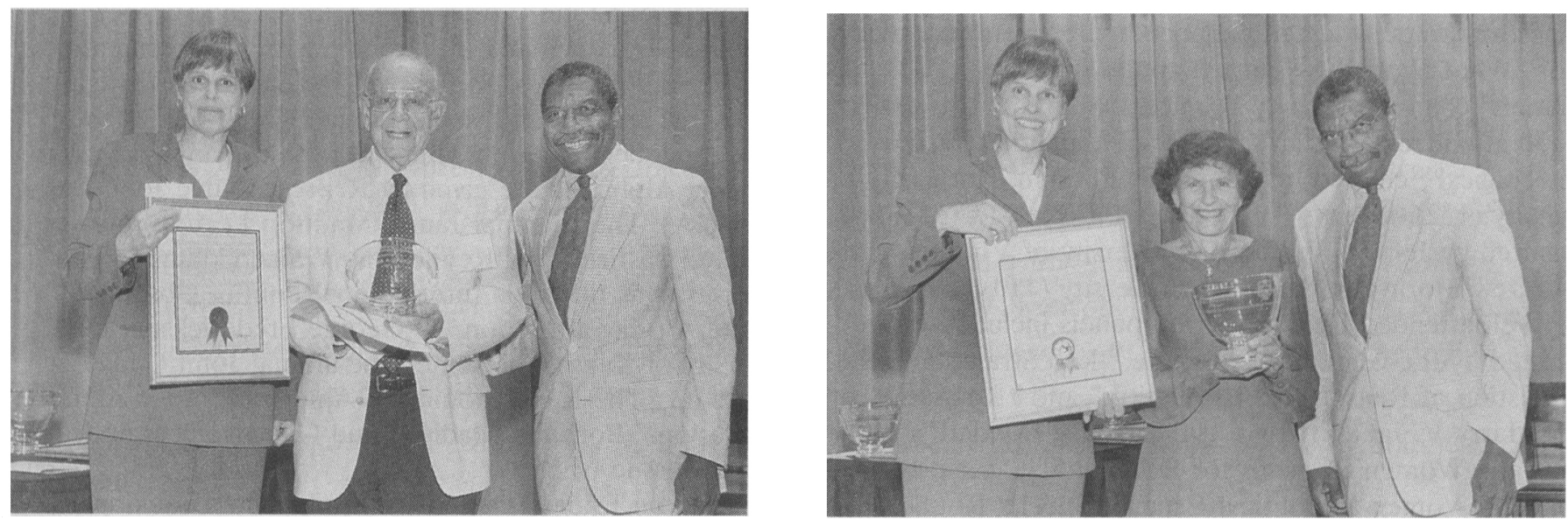
outstanding contributions to both the development of the political science profession and the building of the American Political Science Association.

The Association recognized Gabriel Almond's unique role in recording the intellectual history of the discipline and commenting on the state of the discipline. A former Association president, Almond's leadership contributed to the development of political science abroad and the development of the profession's first code of conduct. Doris Graber was honored as a pathfinder in the area of political communication research and an exemplar of extraordinary service as a teacher, mentor, editor, and association officer. Malcolm Jewel's citation highlighted his contributions to the field of legislative politics, service to the profession, and documentation of the development and growth of the discipline. He was also recognized as a leader in the organization and support of regional and state political science organizations. Thomas Mann was recognized for his efforts to enhance public understanding and appreciation of the institution of Congress. A former APSA Congressional Fellow and executive director, Mann was instrumental in developing Organized Sections and founding the Consortium of Social Science Associations. Each winner was presented with a framed citation and commemorative bowl.

In addition to acknowledging the contributions of the Goodnow Award recipients, the Association

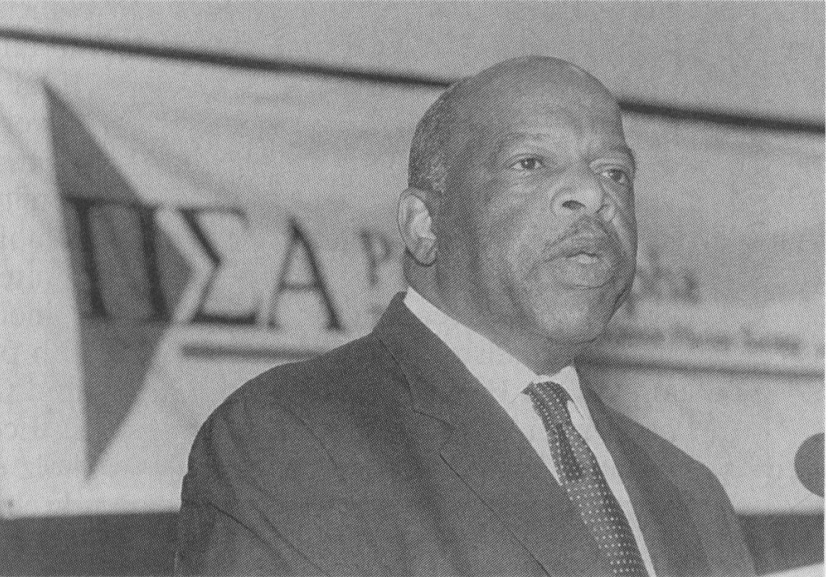

Rep. John Lewis (D-GA) delivers the 1999 Pi Sigma Alpha Lecture. recognized outstanding teaching in the discipline. The Association, and Pi Sigma Alpha, which supported the reception, honored political scientists who received campuswide awards for outstanding teaching during the 1998-99 academic year. More than 100 political scientists received such awards, and out-going APSA President Matthew Holden recognized those who were able to attend the reception. All winners, including those who could not be there in person to receive them, were given a certificate from $\mathrm{Pi}$ Sigma Alpha in recognition of their accomplishment.

Rowman \& Littlefield Publishing Company, which helped sponsor the reception, established the Rowman \& Littlefield Award for Innovative Teaching in 1996 to recognize political scientists who have developed effective new approaches to teaching. L. Sandy Maisel of Colby College, this year's selection committee chair, presented the award to Bernard O'Conner of Eastern Michigan University.
APSA Honors Waltz, Frederickson, and Others with Annual Awards

Recognizing outstanding achievement, the Association honored 22 members of the profession at the APSA Awards Ceremony held in conjunction with the Annual Meeting in Atlanta. Hosted by 1999 Program Co-Chairs John Garcia of the University of Arizona and Alberta Sbragia of the University of Pittsburgh, the major plenary of the meeting drew nearly 500 attendees. Following the ceremony, 1999 APSA President Matthew Holden Jr. delivered his Presidential Address, " 'Progress in Political Research', Revisited."

The Association was pleased to honor Marjorie Mowlam, British Secretary of State for Northern Ireland, with the 1999 Hubert H. Humphrey Award. The Humphrey Committee selected Mowlam in part to recognize her efforts in securing the 1998 Good Friday Agreement.

Mowlam received her Ph.D. in political science from the University of Iowa and later taught at Florida State University and the University of Wisconsin, Milwaukee before returning to England to teach and, later, enter Parliament.

1999 Goodnow Award recipents Malcolm E. Jewell (left-center) and Thomas E. Mann (rightcenter) receive the prize from APSA Executive Director Catherine E. Rudder and 1999 APSA President Matthew Holden Jr. of the University of Virginia
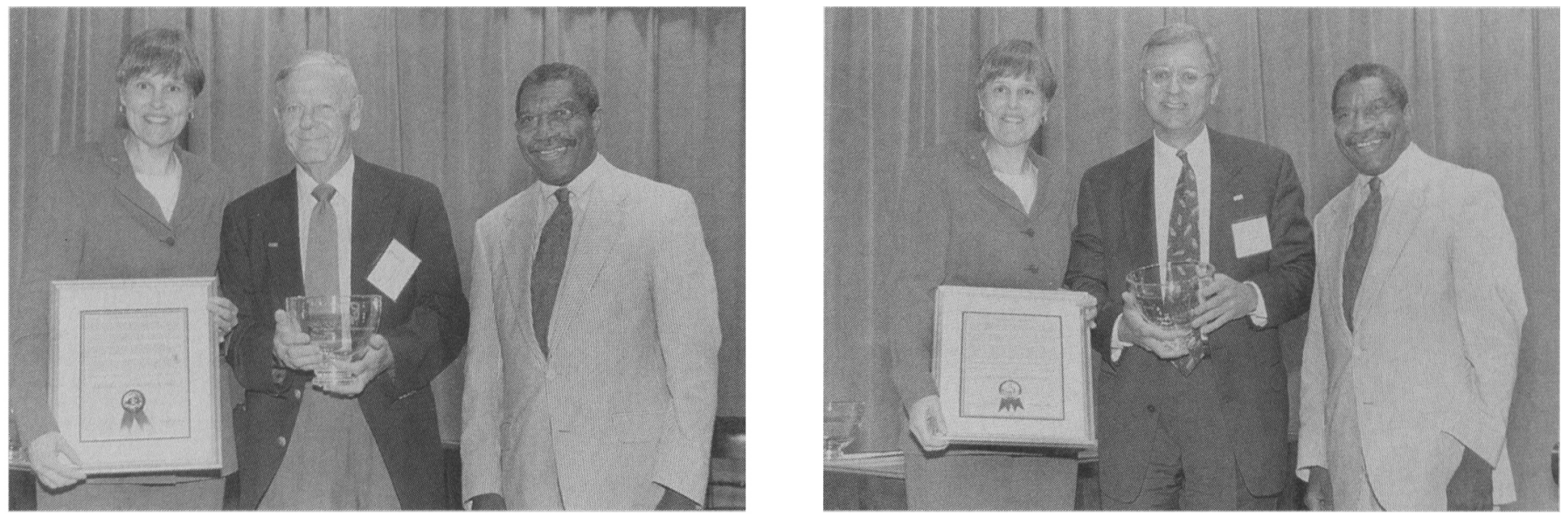